\title{
NIH responds to critics on peer review
}

\section{BETHESDA, MARYLAND}

Responding to hundreds of critical comments, the US National Institutes of Health (NIH) has reversed several controversial proposals made in February as part of a year-long effort to overhaul the agency's peer-review system (see Nature 451, 1035; 2008).

As part of an initiative called Enhancing Peer Review, announced in a finalized form on 6 June, the agency will spend at least $\$ 200$ million annually over the next five years to foster groundbreaking, investigator-initiated research. Of that, at least $\$ 250$ million will go to a new beast: a Transformative R01 Award, a reach-for-the-skies version of the NIH's basic grant. The remaining $\$ 750$ million will go to existing awards that reward risk and innovation: the Eureka, New Innovator and Pioneer awards.

The changes "are concrete solutions that will maximize flexibility, remove any unnecessary burden, stimulate new innovation and promote transformative research", says NIH director Elias Zerhouni.

They include rewards for long-serving reviewers; a streamlined, 12-page R01 grant application, down from 25; and a seven-point, integer scoring scale for grant applications, which will

\section{"Gone is the category} impact, investigators, innova'not recommended for resubmission', for dismal applications." tion, feasibility and environment. Current applications are graded on a 41 point scale, from 1.0 to 5.0 , raising complaints that they claim a degree of accuracy that can't be scientifically defended.

Among the controversial proposals shelved by the agency was a recommendation that all applications, even those on a second or third submission, would be treated as new, without reviewer access to prior reviews.

Gone, too, is the category "not recom- mended for resubmission", which had been suggested for dismal applications. Scientists felt that branding projects with "a clear, checkboxdriven stigma is bad, that it could have unintended consequences", Jeremy Berg, director of the National Institute of General Medical Sciences, told the advisory committee.

Berg and Lawrence Tabak, director of the NIH's dental institute, head the group that developed the recommendations and are charged with implementing them over the next 18 months.

The agency also jettisoned a "minimum effort requirement" that would have required principal investigators to commit at least $20 \%$ of their time to any single NIH grant - an item of particular concern for 'grandee grantees' (see Nature 452, 258-259; 2008). Instead, grantees will need to indicate if they will have more than $\$ 1$ million in cumulative NIH funding.

Meredith Wadman

See also page 838 . 